\title{
MULTIAXIAL FATIGUE EXPERIMENTAL ANALYSIS OF 6063-T66 ALUMINUM ALLOY OF THE BASE MATERIAL AND THE WELDED MATERIAL
}

doi: 10.2478/cqpi-2019-0045

Date of submission of the article to the Editor: 07/05/2019

Date of acceptance of the article by the Editor: 01/06/2019

Milan Uhríčik ${ }^{1}$ - orcid id: 0000-0002-2782-5876

Peter Kopas ${ }^{1}$ - orcid id: 0000-0002-1309-7644

Peter Palček ${ }^{1}$ - orcid id: 0000-0001-7902-2007

Tatiana Oršulová ${ }^{1}$

Patrícia Hanusová1 - orcid id: 0000-0002-5732-7990

1University of Žilina, Faculty of Mechanical Engineering, Slovakia

Abstract: This article deals with determining of fatigue lifetime of aluminum alloy 6063-T66 during by multiaxial cyclic loading. The experiments deal with the testing of specimens for identification of the strain-life behavior of material, the modeling of combined loading and determining the number of cycles to fracture in the region of low-cycle fatigue. Fatigue tests under constant amplitude loading were performed in a standard electromechanical machine with a suitable gripping system. Based on the experimental results the fatigue design curves are compared to the fatigue data from the base material and the welded material and also multiaxial fatigue models, which are able to predict fatigue life at different loads.

Keywords: multiaxial fatigue, aluminum alloy, fatigue criteria, welding, cyclic loading

\section{INTRODUCTION}

In the context of engineering, fatigue is defined as a process of cycle by cycle accumulation of damage in a material undergoing fluctuating stresses and strains. A significant feature of fatigue is that the load is not large enough to cause immediate failure. Instead, failure occurs after a certain number of load fluctuations have been experienced (Bäckström, 2003).

Real loads can induce combined bending, torsional, axial and shear stresses, which can generate bi or tri-axial variable stress/strain histories at the critical point (in general a notch root), causing the so-called multiaxial fatigue problems (Meggiolaro et al., 2009).

Multiaxial fatigue failure is one of the main failure modes of these components and has been widely studied. However, when compared with uniaxial fatigue, multiaxial fatigue presents additional challenges including additional hardening, and effects stemming from normal and shear mean stress. Due to the complexity of failure 
mechanisms in multiaxial fatigue and its dependence on microstructures, there is currently no widely accepted fatigue models used to predict multiaxial fatigue failures (Correia, 2017; Blasón, 2017; Zhu, 2015; Calvente, 2017). According to previous studies, the multiaxial fatigue life prediction models can be summed up into the following categories: the equivalent stress/strain models, energy-based criteria, damage mechanics-based models and critical plane approaches (Yu, 2017).

Welding is used in many industries as an effective and economical method for making structural joints between metal parts. However, the nature of the welding process means that welded joints generally have a fatigue strength that is inferior to that of the parts being joined together. At the same time, welds often tend to be made at geometric features or changes in section in the structure. The result of these facts is that even in a well-designed structure, it is typically the welded joints that are most likely to fail by fatigue. Any evaluation of the durability of a welded structure must therefore place a high priority on a fatigue assessment of the welded joints (HBM nCODE, 2013).

The main focus of the present work is to compare multiaxial fatigue of welded and non-welded specimens and multiaxial fatigue models, which are able to predict fatigue life at different loads.

\section{METHODOLOGY OF RESEARCH}

\subsection{Material}

The research was conducted on an aluminum alloy AIMgSi07.F25, also labeled as EN AW 6063.T66. This alloy has a medium strength and is suitable for applications where no special strength properties are required. Areas of applications are various, for example trailer flooring, heating and cooling pipes, railings, ladders, heat sink sections, etc. The chemical composition of this alloy is shown in Table 1.

Table 1

Chemical composition of the aluminum alloy EN AW 6063.T66 (weight \%)

\begin{tabular}{|c|c|c|c|c|c|c|c|c|}
\hline $\mathbf{S i}$ & $\mathbf{F e}$ & $\mathbf{C u}$ & $\mathbf{M n}$ & $\mathbf{M g}$ & $\mathbf{Z n}$ & $\mathbf{C r}$ & $\mathbf{T i}$ & $\mathbf{A l}$ \\
\hline 0.62 & 0.352 & 0.11 & 0.09 & 0.73 & 0.10 & 0.10 & 0.09 & balance \\
\hline
\end{tabular}

The shape of test bar is shown in Figure 1, where the shape is cylindrical with a diameter $10 \mathrm{~mm}$ and length $150 \mathrm{~mm}$. This test bar had a defined section, in which was expected an increased concentration of stress and creation a fatigue fracture.

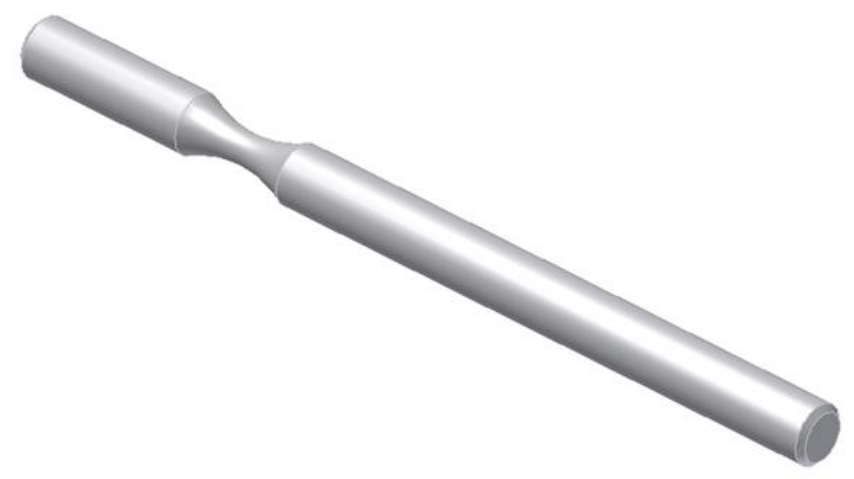

Fig. 1. The shape of a test bar 
Welding was conducted by the tungsten-inert gas (TIG) welding method using a Fronius Magic Wave 2200 welding machine. The used welding factors were: welding current $I_{z}$ $=79 \mathrm{~A}$; welding voltage $U_{z}=18.8 \mathrm{~V}$; diameter of a wolfram electrode $\varnothing=2.4 \mathrm{~mm}$; welding gas $\operatorname{Ar} 99.996 \%$ with gas flow $Q=15 \mathrm{I}_{\mathrm{min}} \mathrm{m}^{-1}$. As a welding wire material there was used aluminium wire AISi5 with diameter $2 \mathrm{~mm}$. The joint strength of TIG-welded joints was evaluated bz fatigue testing, using the test specimens shown in Figure 2 (Kopas and Sága, 2013).

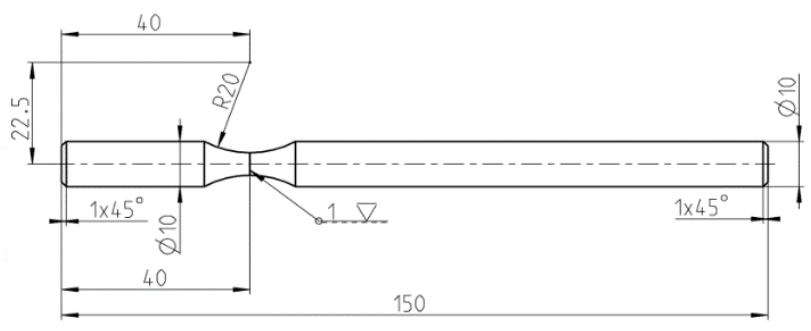

Fig. 2. The fatigue test bar with dimensions and with the indicated weld

\subsection{Equipment}

The design of experimental equipment (Fig. 3) is based on a mechanical principle. The constant rotation is generated by excenter and linkage mechanism. By changing of excentric magnitude it is possible to change a loading magnitude. Also if we change the length of connecting crank on the experimental equipment, there will be a change in the loading cycle character (proportional-non-proportional loading, bending/torsion loading, etc.). Power of the device is secured by two synchronic electromotors with frequency converters from $0.5 \mathrm{~Hz}$ to $100 \mathrm{~Hz}$. Loading frequencies are identical with the frequency of rotation drive. Synchronization of the electromotors is secured by electronics and allows synchronization of the loading amplitude. The synchronization of electromotors also allows setting the phase shift for individual loading levels. There are also two force measurement systems included in the experimental equipment. These systems may be used for measurement of force values during the loading process. For evaluation of fatigue curves it is necessary to know stress and strain conditions on individual loading levels. A sinusoidal waveform was used as command signal (Kopas and Sága, 2013).

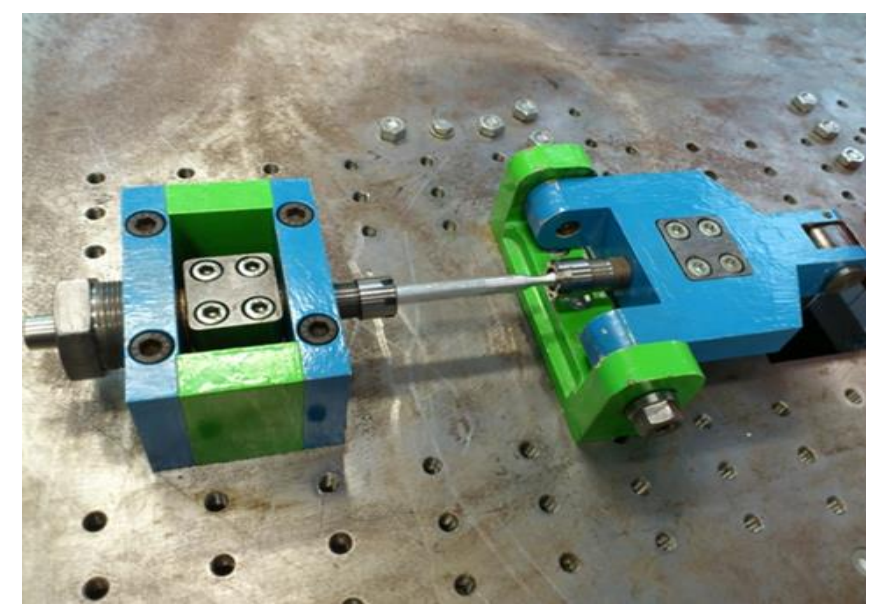

Fig. 3. A gripping attachment of test machine 


\subsection{Multiaxial fatigue criteria}

There are plenty of hypotheses used for evaluating a degree of damage caused by variable load. Life prediction methods which presume homogeneous material (free from cracks, inclusions or defects) at the outset of the investigation can be divided into strain-based (low-cycle fatigue) and stress-based (high-cycle fatigue) methods. Low-cycle fatigue is characterized by repeated plastic strains during cyclic loading conditions where fatigue failure occurs after relative low number of load cycles (in the order of $10^{4}$ cycles). This design approach is normally used in fatigue assessment of local areas where high stress concentrations exist and the material response locally is repeated plastic deformation. In addition, stress-based approaches use the elastic stress range (or amplitude) as the governing load parameter. At a sufficient load level, which may result in a fatigue life of approximately $10^{7}$ cycles, a threshold referred to as the fatigue or endurance limit can be seen for many materials. Research of mechanism and processes of fatigue failure of materials achieves great advance, however there still doesn't exist general failure model, which should be applicable for different conditions of activity (Uhríčik et al., 2014).

Brown and Miller (BM) proposed that both cyclic shear and normal strain on the plane of maximum shear must be considered. The assumption is that cyclic shear strain contributes to nuclear the cracks while the normal strain assists in their growth. It is possible define a Brown-Miller parameter as (Pellinghelli et al., 2018):

$$
\Delta \gamma=\frac{\Delta \gamma_{\max }}{2}+S \Delta \varepsilon_{N}
$$

In line with a Coffin-Manson approach, where elastic and plastic strains are considered separately, it is possible to write the strain-life equation reported below (Pellinghelli et al., 2018):

$$
\frac{\Delta \gamma_{\max }}{2}+S \Delta \varepsilon_{N}=A \frac{\sigma_{f}^{\prime}}{E}\left(2 N_{f}\right)^{2}+B \varepsilon_{f}^{\prime}\left(2 N_{f}\right)^{2}
$$

Fatemi-Socie (FS) criterion, based on that of Brown-Miller, suggests that the normal strain term should be replaced with the normal stress. Moreover, the main difference with Brown-miller criterion is that the fatigue parameter compounds shear and axial components in a multiplicative form, implying that whatever the axial component is, if no shear occurs, the crack does not nucleate. The strain life equation is reported below (Pellinghelli et al., 2018):

$$
\frac{\Delta \gamma}{2}\left(1+k \frac{\sigma_{n, \max }}{\sigma_{y}}\right)=\frac{\tau_{f}^{\prime}}{G}\left(2 N_{f}\right)^{b \gamma}+\gamma_{f}^{\prime}\left(2 N_{f}\right)^{c \gamma}
$$

The two critical plane criteria illustrated above have been developed for materials for which the dominant failure mechanism is shear crack nucleation and growth. The damage model proposed by Smith, Watson and Topper (SWT) regards materials where the failure is mainly related to crack growth on planes of maximum tensile strain or stress. The crack nucleation remains related to shear but the fatigue life of the component is controlled by crack growth on planes perpendicular to the maximum principal stress or strain. SWT model can be used in both proportional or nonproportional loading conditions on a material that fails primarily due to Mode I cracks. 
The SWT parameter can be determined using equation reported below (Pellinghelli et al., 2018):

$$
\sigma_{n, \max } \frac{\Delta \varepsilon_{1}}{2}=\frac{\sigma_{f}^{\prime 2}}{E}\left(2 N_{f}\right)^{2 b}+\sigma_{f}^{\prime} \varepsilon_{f}^{\prime}\left(2 N_{f}\right)^{b+c}
$$

Liu created a virtual model of the deformation energy, which is a generalization of the axial energy on the basis of prediction of fatigue life. Criterion has the following form (Uhríčik et al., 2014):

$$
\Delta W=4 \sigma_{f}^{\prime} \varepsilon_{f}^{\prime}\left(2 N_{f}\right)^{b+c}+\frac{4 \sigma_{f}^{\prime 2}}{E}\left(2 N_{f}\right)^{2 b}
$$

Where: $\gamma_{f}^{\prime}$ is the fatigue ductility coefficient in torsion; $\varepsilon_{f}^{\prime}$ is the fatigue ductility coefficient; $\sigma_{f}$ is the fatigue strength coefficient; $\sigma_{n, \max }$ is the maximum stress; $\sigma_{y}$ is the stress in the direction of the axis $\mathrm{y}^{\prime} \boldsymbol{I}_{f}^{\prime}$ is the fatigue strength coefficient in torsion; $\Delta y_{\max }$ is the maximum shear strain range; $\Delta \varepsilon_{1}$ is the principal strain range; $\Delta \varepsilon_{n}$ is the normal strain range; $\Delta W$ is the virtual strain energy; $b$ is the fatigue strength exponent; $b_{y}$ is the fatigue strength exponent in torsion; $c$ is the fatigue ductility exponent; $c_{Y}$ is the fatigue ductility exponent in torsion; $N_{f}$ is the number of cycles to fracture; $A, B, S, k$ are material parameters; $E$ is the elasticity modulus in tension; $G$ is the elasticity modulus in torsion.

\section{RESULTS AND DISCUSSION}

Eighty specimens were tested under strain controlled conditions in order to identify the strain-life behaviour of the experimental material and they were cyclic loaded under strain control with symmetrical proportional bending-torsion loading, with a nominal strain ratio, $R \varepsilon=-1$. Frequency of each analysis was equal to $30 \mathrm{~Hz}$.

From experimentally measured values of number of cycles to failure of tested structural material EN AW 6063.T66 without and with a welding joint, were created three-dimensional fatigue curve $\varepsilon_{x x}-\gamma_{x y}-N_{t}$, which is shown in Figure 4. The strain amplitude decreases with the increasing number of cycles to failure for both series of aluminum alloy. These performed experiments were to verify fatigue behavior of lowcycle bending and low-cycle torsion loading to obtain relation between strain magnitudes versus number of cycles to failure. The specimen failure criterion during the testing was focused on the creation of fracture area more than $80 \%$ in the measured cross section of the testing rod for both series.

a)

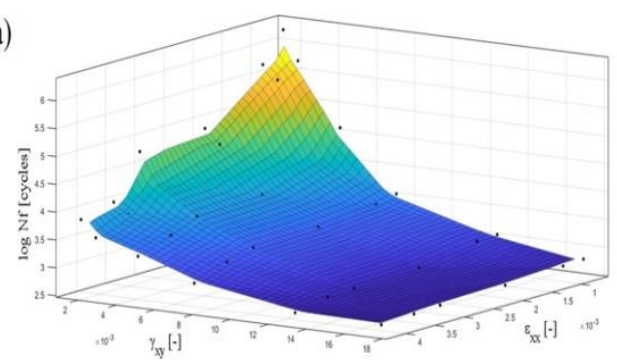

b)

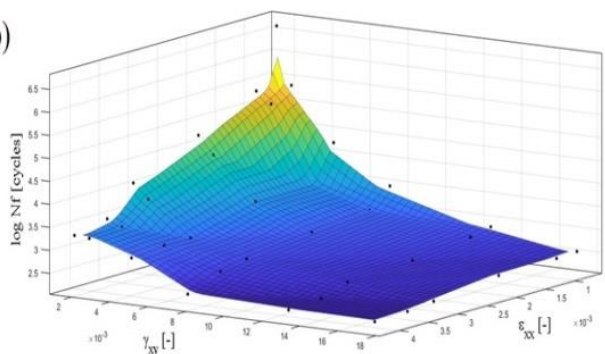

Fig. 4. Three-dimensional fatigue curve $\varepsilon_{x x}-\gamma_{x y}-N_{f}$ for multiaxial low-cycle bending-torsion loading a) of non-welded material, b) of welded material 
In ANSYS software was created the model of the test bar, where ends of this model were loaded by reversed bending moment on the one side and by reversed torsion moment on the opposite site. The values of presented stresses and strains in the middle of the rod radius were taken from computational analysis using finite element method. We used the following parameters in finite element model: used material was aluminum alloy EN AW 6063.T66 (AlMgSi07.F25) with Young's modulus $E=62500$ $\mathrm{MPa}$, Poisson number $\mu=0.3$ and with the strength limit $R_{m}=247 \mathrm{MPa}$. From computational analysis (Fig. 5) can be seen that the area with greatest concentration of stresses or eventually the place with the higher deformation was localized in the middle of the rod radius.

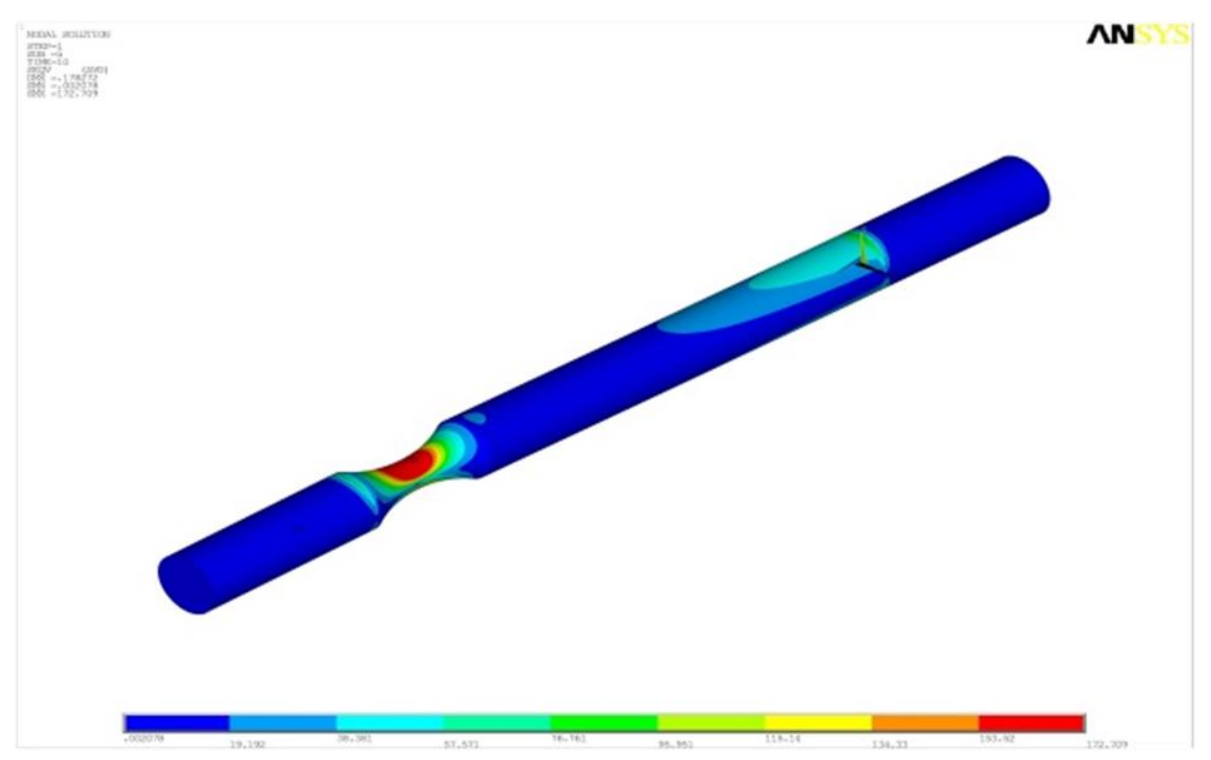

Fig. 5. Result of FEM analysis

Obtained values of the stresses from finite element analysis were next computational analyzed using Fatigue Calculator software (it is a program which can quickly calculate fatigue lifetime of selected material). After starting the calculation, Fatigue Calculator displayed the number of cycles to failure for different models of damage. In our calculation we considered with all multiaxial criteria described above which can be applied to low-cycle fatigue region.

From those calculated values of number of cycles to failure were created threedimensional fatigue curves $\varepsilon_{x x}-\gamma_{x y}-N_{f}$. In Figure 6a is shown a three- dimensional fatigue curve for Brown-Miller criterion, in Figure $6 \mathrm{~b}$ is for Fatemi-Socie criterion, in Figure $6 \mathrm{c}$ is for SWT criterion and in Figure $6 \mathrm{~d}$ is for Liu criterion. 
a)

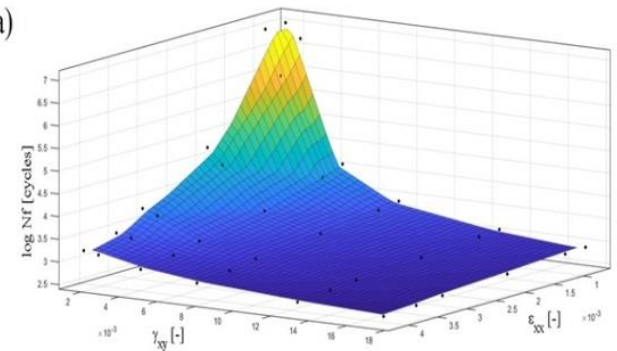

c)

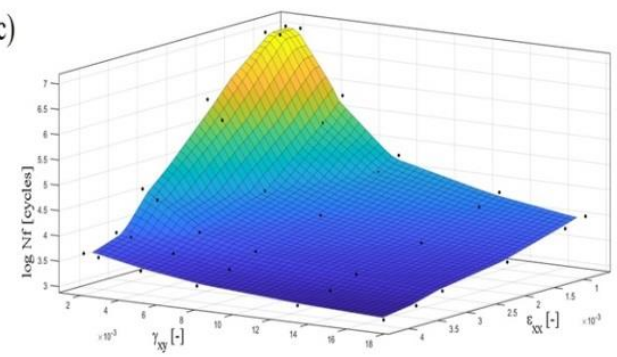

b)

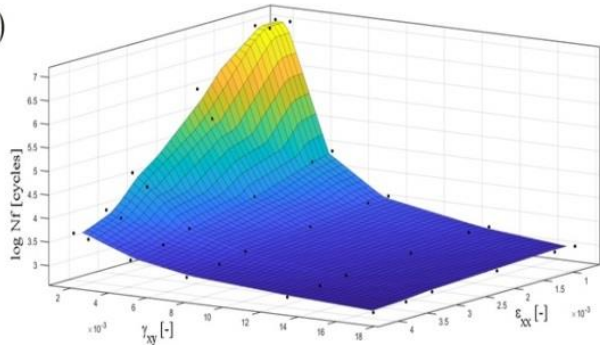

d)

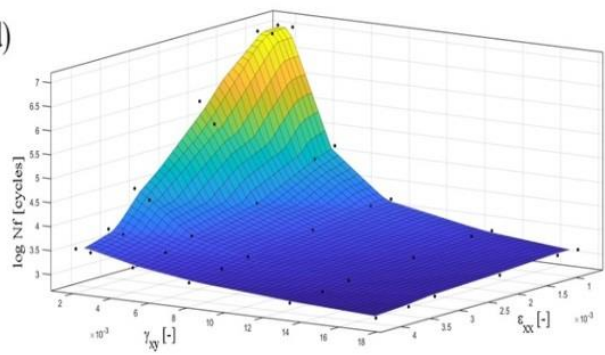

Fig. 6. Three-dimensional fatigue curve $\varepsilon_{x x}-\gamma_{x y}-N_{f}$ for multiaxial a) Brown-Miller criterion, b) Fatemi-Socie criterion, c) Smith-Watson-Topper criterion, d) Liu criterion

\section{CONCLUSION}

Every multiaxial criterion applied to fatigue lifetime calculation and also values of number of cycles to failure from experiments increases with decreasing strain amplitude continuously in the cycles of number region.

Comparing a three-dimensional fatigue curves (from experiments of specimens without and with the welding joint) can be observed, that the curve for the welded specimens gives shorter resistance to fatigue damage than the curve for the base specimens. The decrease in fatigue strength of the welded specimens was attributed to the stress concentration at the toe of weld.

All multiaxial models applied to fatigue lifetime calculation of aluminum alloy EN AW 6063.T66 increases with decreasing strain amplitude continuously in the cycles of number region. For Brown-Miller model it was observed significant decrease of strain amplitude with increasing number of cycles to failure, and globally the fatigue endurance values were markedly lower as for Fatemi-Socie, SWT and Liu damage multiaxial models.

Comparing three-dimensional curves is evident that criteria from Fatigue Calculator give higher lifetime than experiment in the whole area of the number of cycles at the same load amplitudes. This may be caused by different material parameters, which were used for each models of damage. They probably do not include all real parameters and properties of the comparison of the experimental material that probably affected the sensitivity of the numerical calculation.

\section{ACKNOWLEDGEMENTS}

This work has been supported by The Scientific Grant Agency of the Ministry of Education, Science and Sports of the Slovak Republic Academy of Science $N^{\circ}$ $1 / 0398 / 19, N^{\circ} 013 Z ̌ U-4 / 2019$ and Nº 049ŽU-4/2017. 


\section{REFERENCES}

Bäckström, M., 2003, Multiaxial fatigue life assessment of welds based on nominal and hot spot stresses - dissertation, Espoo: Technical research Centre of Finland, Finland

Blasón, S., Muňiz-Calvente, M., Koller, R., Przybilla, C., Fernández-Canteli, A., 2017, Probabilistic assessment of fatigue data from shape homologous but different scale specimens Application to an experimental program, Engineering Fracture Mechanics, 185, 193-209, DOI: 10.1016/j.engfracmech.2017.05.017

Correia, J., Apetre, N., Arcari, A., De Jesus, A., Muňiz-Calvente, M., Calçada, R., Berto, F., Fernández-Canteli, A., 2017, Generalized probabilistic model allowing for various fatigue damage variables, International Journal of Fatigue, 100, 187-194, DOI: 10.1016/j.ijfatigue.2017.03.031

HBM nCode, 2013,Fatigue analysis of seam welded structures using nCode DesignLife, $<$ https://www.ncode.com/images/DesignLife/Downloads/Whitepaper_SeamWelds_ nCodeDesignLife_201303-3.pdf>

Kopas, P., Sága, M., 2013, In-phase multiaxial fatigue experimental analysis of welded cylindrical 6063-T66 aluminium alloy specimens, Manufacturing Technology, 13(1), 59-64.

Meggiolaro, M. A., Pinho de Castro J. T., Miranda, A. C. de O., 2009, Evaluation of multiaxial stress-strain models and fatigue life prediction methods under proportional loading, Mechanics of Solids in Brazil, Brazilian Society of Mechanical Sciences and Engineering, 365-384.

Muňiz-Calvente, M., Blasón, S., Fernández-Canteli, A., De Jesus, A., Correia, J., 2017, A probabilistic approach for multiaxial fatigue criteria, Frattura ed Integrita Strutturale, 11(39), 160-165, DOI: 10.3221/IGF-ESIS.39.16

Pellinghelli, D., Riboli, M., Spagnoli, A., 2018, Full-model multiaxial fatigue life calculations with different criteria, Procedia Engineering, 213, 126-136, DOI: 10.1016/j.proeng.20118.02.014

Uhríčik, M., Kopas, P., Palček, P., 2015, Experimental and numerical analysis of aluminium alloy fatigue lifetime under combined cyclic bending-torsion loading, $32^{\text {th }}$ International Colloquium - Advanced manufacturing and repair Technologies in vehicle industry, Svojanov, Czech republic, 45-52.

Yu, Z.-Y., Zhu, S.-P., liu, Q., Liu, Y., 2017, Multiaxial fatigue damage parameter and life prediction without any additional material constants, Materials, 10(8), 923 DOI: 10.3390/ma10080923

Zhu, S.-P., Huang H.-Z., Li, Y., Liu, Y., Yang, Y., 2015, Probabilistic modelling of damage accumulation for time-dependent fatigue reliability analysis of railway axle steels, Proceedings of the Institution of Mechanical Engineers, Part F: Journal of Rail and Rapid Transit, 229(1), 23-33, DOI: 10.1177/0954409713496772 